\title{
Men and women with chronic major depression responded differently to sertraline and imipramine
}

Kornstein SG, Schatzberg AF, Thase ME, et al. Gender differences in treatment response to sertraline versus imipramine in chronic depression. Am J Psychiatry 2000 Sep;157:1445-52.

\section{QUESTION: Do men and women with chronic depression have different treatment responses to selective serotonin reuptake inhibitors (SSRIs) (eg, sertraline) and tricyclic antidepressants (TCAs) (eg, imipramine)?}

\section{Design}

Randomised \{allocation concealed*\} $\uparrow$, blinded \{clinicians, patients, and outcome assessors $\} \uparrow^{*}$, controlled trial with 12 weeks of follow up.

Source of funding: Pfizer Pharmaceuticals.

For correspondence: Dr S G Kornstein, Department of Psychiatry, Medical College of Virginia, Virginia

Commonwealth

University, PO Box

980710, Richmond, VA

23298-0710, USA.

$\mathrm{Fax}+1804828$

5644.

\section{Setting}

10 university medical centres and 2 clinical research centres in the US.

\section{Patients}

400 women (mean age $40 \mathrm{y}$ ) and 235 men (mean age 43 y) who were $21-65$ years of age and met DSM-III-R criteria for chronic major depression or double depression. Follow up was $80 \%$; analysis of all patients was done using last observation carried forward.

Sertraline and imipramine for chronic major depression at 12 weeksł

Table 1 Sertralinev imipramine in women

\begin{tabular}{lllll} 
Outcomes & Sertraline & Imipramine & RRR (95\% CI) & NNT (CI) \\
Dropout rate & $14 \%$ & $26 \%$ & $47 \%(20$ to 65$)$ & $9(5$ to 24$)$ \\
\hline & & & RBI (CI) \\
\hline Treatment response & $57 \%$ & $46 \%$ & $23 \%(0.46$ to 54$)$ & $10(5$ to 435$)$ \\
\hline
\end{tabular}

Table 2 Imipramine vertraline in men

\begin{tabular}{|c|c|c|c|c|}
\hline Outcomes & Imipramine & Sertraline & RRR (CI) & NNT (Cl) \\
\hline Dropout rate & $19 \%$ & $24 \%$ & $20 \%(-34$ to 54$)$ & Not significant \\
\hline & \multicolumn{4}{|c|}{$\mathrm{RBI}(\mathrm{Cl})$} \\
\hline Treatment response & $62 \%$ & $45 \%$ & $37 \%(6.2$ to 75$)$ & 6 (4 to 35$)$ \\
\hline
\end{tabular}

\section{Intervention}

Patients were allocated to sertraline, $50 \mathrm{mg} /$ day initially ( $\mathrm{n}=264$ women and $162 \mathrm{men}$ ) or imipramine, $50 \mathrm{mg} /$ day initially ( $\mathrm{n}=136$ women and $73 \mathrm{men})$. Doses could be increased to a maximum of $200 \mathrm{mg}$ /day for sertraline (mean dose $139.6 \mathrm{mg} / \mathrm{d}$ for women; $143.2 \mathrm{mg} / \mathrm{d}$ for men) and a maximum of $300 \mathrm{mg} /$ day for imipramine (mean dose $196.3 \mathrm{mg} / \mathrm{d}$ for women; $207.5 \mathrm{mg} / \mathrm{d}$ for men).

\section{Main outcome measures}

Dropout rates and treatment response $(50 \%$ decrease in Hamilton Depression Rating Scale [HDRS] score, HDRS score $\leqslant 15$, a Clinical Global Impression [CGI] severity scale score $\leqslant 3$, and a CGI improvement scale score of 1 or 2).

\section{Main results}

A statistically significant interaction effect was found between treatment and sex for rates of dropout $(p=0.009)$ and treatment response $(p=0.001)$. Women taking sertraline had lower dropout rates than women taking imipramine $(\mathrm{p}=0.002)$, whereas no difference was seen between groups among men (table 1 and 2 ). Women had a greater response rate in the sertraline group than in the imipramine group $(\mathrm{p}=0.02)$, and men had a greater response rate in the imipramine group than in the sertraline group $(\mathrm{p}=0.04)($ table 1 and 2$)$.

\section{Conclusions}

In patients with chronic depression, sertraline was more effective than imipramine and led to fewer dropouts in women; imipramine was more effective than sertraline in men.

*See glossary.

†Information provided by author.

\section{COMMENTARY}

As we all know, men and women are different. One of these sex differences occurs in mood disorders: depression is approximately twice as common in women as men. Mood disorder in women is also a subject of serious academic study and the focus of a major new textbook. ${ }^{1}$ The increase in depression rates in women becomes evident after puberty, and it is argued that the difference lessens after menopause. Given these findings, sex based differences in treatment response are of great interest. Such differences are important because unipolar depression is such a large public health problem, ranking second in developed market economies in recent global burden of disease studies. ${ }^{2}$

Previous studies have suggested that women might be more responsive to serotonergic agents, and the study by Kornstein $e t$ al is a timely addition to this literature. It shows fairly convincingly that women have a better response to SSRIs and men a better response to TCAs. The authors comment on the possible reasons for this, especially because the differing response rate was observed primarily in premenopausal women. Obviously, the female sex hormones and the menstrual cycle may play a role in determining this phenomenon.

This finding has potentially important implications for clinical practice. Although reasons still exist (eg, side effect profile, safety in overdose) to choose an SSRI as a first line agent in men, this study reminds us that TCAs may still have a place in psychiatry, and that sex should be added to the list of factors to consider when selecting an antidepressant. This study was completed under contract from Pfizer Pharmaceuticals, the makers of sertraline, and this article may enhance the sales profile of sertraline. The relationship between the pharmaceutical industry and medical academics has recently come under the spotlight. ${ }^{3}$ Because of the clear commercial implications and potentially increased healthcare costs, it is important that this study be independently replicated.

Allan H Young, MBChB, MPhil, PhD, MRCPsych Royal Victoria Infirmary, University of Newcastle Newcastle upon Tyne, UK

1 Steiner M, Yonkers KA, Eriksson E. Mood disorders in women. London: Martin Dunitz, 2000;573.

2 Murray CJ, Lopez AD. Global mortality, disability, and the contribution of risk factors: global burden of disease study. Lancet 1997;349:1436-42.

3 Jackson T. Marketing: are you being duped? BMJ 2001:322:1312. 